\title{
A trajetória do Programa de Estudos em Gestão Social (Pegs)
}

\author{
Fernando G. Tenório*
}

\section{Introdução}

Na mesa-redonda The management of social services, realizada na Dinamarca em julho de 1991, foi proposto àquelas instituições que ensinavam administração, que colocassem à disposição dos movimentos sociais tecnologias gerenciais para melhorar sua capacidade de negociação com o Estado e com a sociedade de uma maneira geral. Para garantir o desenvolvimento e a consolidação dessa proposta, no ano seguinte foi realizado, na cidade de Santa Cruz de La Sierra (Bolívia), o Seminário Ibero-Americano de Formação de Professores em Gestão Social.

Motivadas por essas intenções, algumas instituições de ensino e pesquisa em administração pública e empresarial, de nível nacional e internacional, têm direcionado suas atividades para a formação e capacitação de gerentes, técnicos e lideranças comunitárias. Essas instituições têm desenvolvido programações acadêmicas e de treinamento nas áreas de planejamento e implementação de políticas sociais e nas áreas onde primeiro, segundo e terceiro setores sejam convergentes com o conceito de gestão social. Na então denominada Escola Brasileira de Administração Pública da Fundação Getulio Vargas (Ebap/FGV) é criado o Programa de Estudos em Gestão Social (Pegs). Suas atividades começaram no primeiro semestre de 1990, com um estudo sobre projetos comunitários e a participação de dois alunos do Curso de Mestrado em Administração Pública, resultando na publicação, em 1991, do livro Elaboração de projetos comunitários: uma abordagem prática.

* Coordenador do Pegs. Endereço: Praia de Botafogo, 190, sl. 426-G - CEP 22250-900, Rio de Janeiro, RJ, Brasil. E-mail: tenorio@fgv.br. 
O tema gestão social tem sido objeto de estudo e prática muito mais associado à gestão de políticas sociais, de organizações do terceiro setor, do combate à pobreza e até ambiental, do que à discussão e possibilidade de uma gestão democrática, participativa, quer na formulação de políticas públicas, quer nas relações de caráter produtivo. No Pegs, entretanto, o conceito de gestão social é entendido como o processo gerencial dialógico onde a autoridade decisória é compartilhada entre os participantes da ação. O adjetivo social qualificando o substantivo gestão é percebido como o espaço privilegiado de relações sociais onde todos têm direito à fala, sem nenhum tipo de coação. Desde sua criação, suas atividades vêm se expandindo e orientando suas ações a partir dos seguintes pares de palavras-categorias: Estado-sociedade, capital-trabalho e mercadosociedade, ${ }^{1}$ assim como gestão estratégica, gestão social e cidadania deliberativa.

No que diz respeito aos três primeiros pares de palavras - Estado-sociedade, capital-trabalho e mercado-sociedade, inverteu-se as posições dessas referências de estudo para sociedade-Estado, trabalho-capital e sociedade-mercado. Aparentemente, tais mudanças de posição não configurariam substantivas alterações. No entanto, na compreensão do Pegs, elas promovem uma alteração fundamental, à medida que pretendem sinalizar que a sociedade e o trabalho devem ser também os protagonistas dessa relação, já que historicamente tem sido o inverso. Tal inversão não é para restar importância ao Estado ou ao mercado, mas sim enfatizar o papel da sociedade civil e do trabalho nessa interação.

Quanto ao par gestão estratégica e gestão social, eles significarão que o primeiro atua determinado pelo mercado, portanto, é um processo de gestão que prima pela competição, onde o outro, o concorrente, deve ser excluído e o lucro é o seu motivo. Contrariamente, a gestão social deve ser determinada pela solidariedade, portanto, é um processo de gestão que deve primar pela concordância, onde o outro deve ser incluído e a cooperação o seu motivo. Enquanto na gestão estratégica prevalece o monólogo — o indivíduo; na gestão social deve sobressair o diálogo - o coletivo.

A definição de gestão social, portanto, vai estar apoiada na compreensão da inversão desses pares de palavras, bem como do conceito de cidadania

\footnotetext{
${ }^{1}$ A expressão sociedade, nos estudos do Pegs, tanto poderá significar a delimitação de um determinado espaço socioeconômico-político-cultural, ou a sociedade civil entendida como aquele espaço social formado por diferentes organizações de natureza não-estatal e não-econômica, ou ainda, movimentos sociais em contraste com o Estado e o mercado. Apesar da expressão capital significar a forma que determina a macroorganização de uma sociedade, aqui indica também os agentes econômicos (mercado) que processam a oferta e a demanda de produtos ou serviços.
} 
deliberativa, categoria intermediadora da relação entre os pares de palavras, que vai significar que a legitimidade das decisões deve ter origem em espaços de discussão orientados pelos princípios da inclusão, do pluralismo, da igualdade participativa, da autonomia e do bem comum. Espaços onde se articulam diferentes atores que vocalizam as suas pretensões com o propósito de planejar, executar e avaliar políticas públicas ou decisões de produção. Assim, entendemos gestão social como o processo gerencial decisório deliberativo que procura atender às necessidades de uma sociedade, região, território ou sistema social específico, quer vinculado à produção de bens quer à prestação de serviços.

\section{Objetivos do Pegs}

São eles:

、 desenvolver atividades de ensino, pesquisa e extensão a fim de institucionalizar o campo de estudos em gestão social nas relações sociedade-Estado, trabalho-capital e sociedade-mercado;

v elaborar material conceitual e instrumental que auxilie diferentes organizações e sujeitos sociais, na gestão de políticas, planos, programas e projetos de natureza social;

v capacitar gerentes e técnicos de organizações do primeiro, segundo e terceiro setores, no conhecimento do referencial teórico-prático em gestão social;

v transferir, socialmente, tecnologias gerenciais para organizações do terceiro setor e movimentos sociais.

\section{O Pegs conceitualmente}

Os elementos conceituais que orientam a reflexão do Pegs se desenvolveram a partir de uma epistemologia que procura reconstruir o conhecimento por meio da produção social e não como resultado de saberes oniscientes. Tal epistemologia tem compromisso voltado para questões intersubjetivas e permite inferir que o discurso e a prática da gestão social têm sido pautados pela lógica do mercado, da gestão estratégica, e não por questões de natureza social. Enquanto a gestão estratégica procura objetivar o "adversário" por meio da esfera privada, a 
gestão social deve atender, por meio da esfera pública, ao bem comum da sociedade.

Dentro dessa abordagem, o programa buscou nas reflexões, primeiramente, de pensadores brasileiros, como Alberto Guerreiro Ramos e, posteriormente, da teoria crítica da escola de Frankfurt, principalmente da segunda geração, tendo como referência Jürgen Habermas.

Alberto Guerreiro Ramos critica a existência do mercado na condição de única via de regulação e interação social. Aponta para a possibilidade e a necessidade de além do mercado outras formas de interação social a partir de uma lógica diferente do utilitarismo.

Ele defende a tese que uma teoria da organização centrada no mercado não é aplicável a todos os tipos de relações que comportam a sociabilidade humana, mas apenas a um tipo especial de atividade. Para ele, a aplicação dos princípios mercantis a todas as formas de atividades estaria dificultando a atualização de possíveis novos sistemas sociais, necessários à superação de dilemas básicos de nossa sociedade.

Seu principal argumento é que a ciência social estabelecida também se fundamenta numa racionalidade instrumental, particularmente característica do sistema de mercado. Para ele a teoria da organização, tal como é hoje conhecida, é menos convincente do que foi no passado e, mais ainda, torna-se pouco prática e inoperante, à medida que continua a se apoiar em pressupostos ingênuos.

O modelo multidimensional de análise social é concebido para contrapor o que ele chama de modelo unidimensional das ciências, que enfatiza o mercado como único meio alocador de recursos e intermediários das relações produtivas e sociais. A multidimensionalidade proposta pelo autor está ancorada numa pluralidade de enclaves sociais no sentido de que o indivíduo consiga alcançar sua realização pessoal nos múltiplos aspectos. Assim, o conceito de gestão social desenvolvido pelo Pegs leva em consideração os diversos enclaves da vida social (econômico, social, cultural, territorial etc.) no processo de gestão.

Dessa forma, o entendimento acerca de gestão social vem reforçar suas características políticas, contrapondo-a a gestão estratégica. Esse modelo de gestão é "um tipo de ação social utilitarista, fundada no cálculo de meios e fins e implementada através da interação de duas ou mais pessoas, na qual uma delas tem autoridade formal sobre a(s) outra(s)" (Tenório, 1998). A gestão social contrapõe-se à gestão estratégica à medida que propõe "um gerenciamento mais participativo, dialógico, no qual o processo decisório é exercido por meio de diferentes sujeitos sociais" (Tenório, 1998:16). 
A partir disso, o Pegs foi buscar outro referencial teórico: o da ação comunicativa sugerida por Jürgen Habermas. Esse autor desenvolve na teoria da ação comunicativa uma análise teórica e epistêmica da racionalidade como sistema operante da sociedade. Nesse sentido, deve-se analisar sua tese como contraposição da razão instrumental. Na idéia de mundo da vida, Habermas mostra a racionalidade dos indivíduos mediada pela linguagem e comunicatividade. Esses elementos se constituem em instrumentos de construção racional dos sujeitos, calcados na estruturação de três universos: o objetivo, o subjetivo e o social, onde o acordo sobre decisões é alcançado por meio de capacidades argumentativas e da deliberação democrática (Habermas, 1987).

Habermas fundamenta a reabilitação da esfera social, com base na idéia de orientações dialógicas das ações sociais e, dessa forma, isso não poderia ser feito de modo coercitivo ou meramente instrumental, mas por um comportamento interativo, compreensivo e democrático na órbita de um consenso comunicativo, que deveria ser construído dentro das relações sociais em função das racionalidades das ações. De forma reducionista, pode-se dizer que isso é o início da racionalidade comunicativa, ou pelo menos um caminho que a precede.

Para fundamentar seus pressupostos teóricos, Habermas busca na razão dois fundamentos que darão suporte à sua teoria: comunicatividade e mundo da vida; e com isso ele estabelece o seu conceito de racionalidade. No esforço de conceituar a racionalidade comunicativa, Habermas tenta abranger as várias manifestações de razão dos indivíduos em todo seu aspecto, na relação com o mundo, tanto nas ações diretas do relacionamento do homem com a sociedade de uma forma geral, quanto nas expressões simbólicas que intermediam a relação do sujeito com o mundo onde vive.

O Pegs parte desses princípios para defender a tese de que o cidadão é o sujeito privilegiado de vocalização daquilo que interessa à sociedade nas demandas ao Estado e daquilo que interessa ao trabalhador na interação com o capital. Isto é, a cidadania é vista não apenas como a base da soberania de um Estado-nação, mas também como expressão do pleno exercício de direitos exigíveis em benefício da pessoa e da coletividade. Assim,

o conceito de gestão social não está atrelado às especificidades de políticas públicas direcionadas a questões de carência social ou de gestão de organizações do denominado terceiro setor mas, também, a identificá-lo como uma possibilidade de gestão democrática, onde o imperativo categórico não é apenas o eleitor e/ou contribuinte, mas sim o cidadão deliberativo; não é só a economia de mercado, mas também a economia social; não é o cálculo utilitário, mas o consenso solidário; não é o assalariado como mercadoria, mas o trabalhador como sujeito; não é somente a produção como valor de troca, mas igualmente como valor de uso; 
não é tão-somente a responsabilidade técnica mas, além disso, a responsabilidade social; não é a res privada, mas sim a res publica; não é o monólogo mas ao contrário, o diálogo.

(Tenório, 2005)

Dessa forma, o Pegs defende a idéia de que a participação deve estar presente nas estratégias de gestão, tanto do ponto de vista da administração de empresas privadas (relação trabalho-capital), quanto do ponto de vista da administração pública (relação sociedade-Estado). Como elemento básico para a eficácia do processo participativo, Pedro Demo (2001) destaca que não há participação imposta, concedida ou doada, pois sua legitimidade encontra-se na conscientização de sua importância, da negociação de espaços para seu exercício e do estabelecimento de regras que democraticamente vão delimitar a prática.

Sob o mesmo ponto de vista, Tenório e Rozenberg (1997) afirmam que quando a participação é concedida, dificilmente se verifica um processo de internalização desse direito por parte dos beneficiários. A participação requer consciência sobre os atos e que os envolvidos possuam compreensão do processo que estão vivenciando. Pois, para os autores, somente a participação consciente possibilita o reconhecimento das relações de interesse e poder que estão associadas ao processo participativo. Tenório e Rozenberg (1997:104) afirmam que "a participação, portanto, deve ser vista como o grande instrumento de acesso à cidadania. Em sua plenitude, a cidadania só se consolida na presença de uma participação entendida como a ação coletiva e exercício consciente, voluntário e conquistado".

Observa-se, assim, que a participação tem relação direta com o conceito de cidadania deliberativa. A partir do momento em que esse processo deva se dar pela reivindicação dos atores sociais e não por uma concessão do poder público, os estudos do Pegs indicam que a participação tem como pressuposto o fortalecimento da sociedade civil. Essa perspectiva coloca o desafio que durante a década de 1990 esteve na contramão da história: pensar uma sociedade voltada para o coletivismo em lugar do individualismo da sociedade de mercado; um Estado como facilitador da participação em lugar do Estado tecnoburocrático ou ainda "gerencial"; um mercado comprometido com o desenvolvimento e responsabilidade social, em lugar de uma prática autocentrada, privatista e patrimonialista.

\section{Metodologia de trabalho do Pegs}

O processo de trabalho do Pegs, quando orientado a projetos de pesquisa, tem utilizado os seguintes métodos: pesquisa-ação, análise das representações so- 
ciais e estudo de casos; quanto aos processos de capacitação, tem como referencial básico o método de Paulo Freire e metodologias participativas como o Zopp, do alemão Ziel Orientierte Projekt Planung - Planejamento de Projetos Orientado por Objetivos. A fim de atender a essa proposta de trabalho, o Pegs vem desenvolvendo suas ações com a participação direta de alunos dos cursos de graduação, mestrado em administração pública, mestrado executivo e do doutorado em administração, além de bolsistas Pibic/CNPq. A seguir apresenta-se a lista da produção do Pegs nestes 16 anos de existência.

\section{Produção do Pegs}

\section{Pesquisas}

- Administração de projetos comunitários. Apoio do Centro Latino-Americano de Administración para el Desarrollo (Clad), jun. 1991 a jun. 1992.

v Administração pública e o terceiro setor: as experiências do Programa Gestão Pública e Cidadania. Apoio FGV e Fundação Ford, out. 1999 a out. 2000.

- Avaliação da reforma administrativa do governo Collor: uma análise dos 100 primeiros dias, em colaboração, executada pela Ebape/FGV, $2^{\underline{0}}$ semestre de 1990.

、 Avaliação de projetos comunitários. Jun. 1992 a dez. 1993.

- Banco de dados em gestão social. Apoio CNPq, set. 1997 a set. 1999.

- Cidadania e desenvolvimento local. Apoio do Propesquisa-Ebape e do Programa Gestão Pública e Cidadania (PGPC) da Eaesp. Início em out. 2002.

、 Elaboração de projetos comunitários. Apoio da Cáritas Arquidiocesana do Rio de Janeiro, mar. 1990 a mar. 1991.

- Escritório modelo de elaboração de projetos comunitários. Apoio Cáritas Arquidiocesana do Rio de Janeiro, $2^{\underline{O}}$ semestre de 1997 a $2^{\underline{O}}$ semestre de 1998.

、 Gestão de organizações não-governamentais. Set. 1994 a dez. 1995.

- Metodologias participativas, experiências em gestão pública e cidadania. Apoio PGPC, $1^{\circ}$ semestre de 1998. 
- Metodologias participativas, experiências. Apoio do PGPC, $2^{\underline{O}}$ semestre de 1996.

- Participação cidadã na gestão pública: práticas e representações sociais. Estudo dos casos Nova Friburgo e Rio de Janeiro. Apoio Fundação João Goulart e Fundação Kellog, 1997 a 2000.

- Realidade urbana no Brasil: poder local - banco de dados. Apoio do Centro de Estatística Religiosa e Investigações Sociais (Ceris), jul. 1993 a ago. 1994.

- As recentes transformações do mundo do trabalho: o caso das cooperativas de transporte na Região Metropolitana do Rio de Janeiro. Apoio CNPq, out. 1999 a out. 2001.

- Responsabilidade regulada e responsabilidade social: estudo de caso em empresas siderúrgicas. Apoio CNPq/Propesquisa-Ebape, mar. 2002 a mar. 2004.

\section{Publicações}

\section{Livros}

- Administração de projetos comunitários: uma abordagem prática. Rio de Janeiro/São Paulo: Cedac-Loyola, 1995.

- Avaliação de projetos comunitários: uma abordagem prática. Rio de Janeiro/São Paulo: Cedac-Loyola, 1995.

v Desenvolvimento local e cidadania. Ijuí (RS): Unijuí. (no prelo).

- Elaboração de projetos comunitários: uma abordagem prática. Rio de Janeiro/São Paulo: Cedac-Loyola, 1995.

- Um espectro ronda o terceiro setor, o espectro do mercado: ensaios de gestão social. 2. ed. rev. Ijuí: Unijuí, 2004.

- Flexibilização organizacional, mito ou realidade? 2. ed. Rio de Janeiro: FGV, 2003.

- Flexibilização organizacional: aplicação de um modelo de produtividade total. Rio de Janeiro: FGV, 2002. 
- Gestão de ONGs: principais funções gerenciais. 8. ed. Rio de Janeiro: FGV, 2003.

v Gestão social: metodologias e casos. 4. ed. Rio de Janeiro: FGV, 2004.

、 Responsabilidade social empresarial: teoria e prática. 2. ed. rev. Rio de Janeiro: FGV, 2006.

- Tecnologia da informação transformando as organizações e o trabalho. Rio de Janeiro: FGV. (no prelo).

\ Tem razão a administração? Ensaios de teoria organizacional. 2. ed. rev. Ijuí: Unijuí, 2004.

\section{Capítulos de livros}

v Assimetria na relação eu-tu. In: AGOSTINHO, Márcia E. et al. (Orgs.). Convivencialidade: a expressão da vida nas empresas. São Paulo: Atlas, 2002. p. 81-91.

v Cidadania deliberativa: um estudo de caso. In: JACOBI, Pedro; PINHO, José Antonio (Coords.). Inovação no campo da gestão pública local: novos desafios, novos patamares. Rio de Janeiro: FGV, 2006.

v Escorços sobre a gestão pública e gestão social. In: MARTINS, Paulo Emílio M. Estado e gestão pública. Rio de Janeiro: FGV, 2006.

V (Re)visitando o conceito de gestão social. In: ADDOR, Felipe; LIANZA, Sidney (Coords.). Tecnologia e desenvolvimento social e solidário. Porto Alegre: UFRGS, 2005.

\section{Artigos}

、 Aliança e parceria: uma estratégia em Alves \& Cia. Revista de Administração Pública, Rio de Janeiro: FGV, v. 34, n. 3, p. 35-52, maio/jun. 2000.

v Avaliação institucional: perspectivas e tendências. In: SIMPÓSIO NACIONAL SOBRE AVALIAÇÃO EDUCACIONAL: UMA REFLEXÃO CRÍTICA. Anais... Rio de Janeiro: Cesgranrio, 1993.

、 Banco de dados sobre as relações trabalho-capital e sociedade-Estado. Cadernos EBAP, Rio de Janeiro: FGV, n. 97, ago. 1999. 
v Banco de dados sobre as relações trabalho-capital e sociedade-Estado. Cadernos EBAP, Rio de Janeiro: FGV, n. 99, out. 1999.

、 Bases conceituais e metodológicas para o estudo da participação cidadã na gestão pública: entre práticas e representações sociais. Cadernos EBAP, Rio de Janeiro: FGV, n. 93, mar. 1999.

v Cidadania e desenvolvimento local: casos brasileiros. In: CONGRESO INTERNACIONAL DEL CLAD, 9. Anales... Madrid, 2004.

、 Cidadania e desenvolvimento local: o caso do município de São João (PE) - Brasil. In: CONGRESO INTERNACIONAL DEL CLAD, 9. Anales... Madrid, 2004.

v Cidadania e trabalho. RAP, Rio de Janeiro: FGV, v. 32, n. 5, set./out. 1998.

v Cidadania, desenvolvimento local e redes sociais: um estudo em Minas Gerais. In: ENCONTRO NACIONAL DA ASSOCIAÇÃO NACIONAL DE PÓSGRADUAÇÃO EM ADMINISTRAÇÃO, 29. Anais... Brasília, 2005.

v Ciudadania deliberativa: un estudio de caso. Revista Chilena de Administración Pública, Santiago do Chile (Chile): Universidad del Chile, v. 2, n. 5, 2003/2004.

v Contiene dialogicidad la calidad? Un análisis crítico de la calidad total. Reforma y Democracia, Caracas: Centro Latinoamericano de Administración para el Desarrollo, n. 6, p. 183-206, jul. 1996.

v Um espectro ronda o terceiro setor: o espectro do mercado. RAP, Rio de Janeiro: FGV, v. 33, n. 5, p. 85-102, set./out. 1999.

、 O Estado empresário brasileiro, notas histórico-ideológicas. Cadernos EBAP, Rio de Janeiro: FGV, n. 85, jul. 1997.

v Flexibilização organizacional, mito ou realidade? In: ENCONTRO NACIONAL DA ASSOCIAÇÃO BRASILEIRA DE ESTUDOS DO TRABALHO (ABET), 5. Anais... Rio de Janeiro: Abet, 1997.

、 A flexibilização da produção significa a democratização do processo de produção? In: ENCONTRO ANUAL DA ASSOCIAÇÃO NACIONAL DOS PROGRAMAS DE PÓS-GRADUAÇÃO EM ADMINISTRAÇÃO, 18. Anais... Curitiba, 1994.

v Gestão de Recursos Humanos: gerenciamento do impacto da tecnologia da informação no setor de serviços, uma amostra. In: ENCONTRO DA ANPAD, 24. Anais... Florianópolis, 2000. 
V Gestão pública e cidadania: metodologias participativas em ação. RAP, Rio de Janeiro: FGV, v. 31, n. 4, p. 101-125, jul./ago. 1997.

v Gestão social e desenvolvimento local: uma perspectiva a partir da cidadania deliberativa. In: ENCONTRO DA ASSOCIAÇÃO NACIONAL DE PÓSGRADUAÇÃO E PESQUISA (ENANPAD). Anais... Curitiba, 2004.

、 Gestão social: uma perspectiva conceitual. RAP, Rio de Janeiro: FGV, v. 32, n. 5, set./out. 1998.

、 A gestão universitária no contexto atual. Cadernos de Avaliação Institucional, Ijuí: Unijuí, dez. 1997.

、 Gestión pública o gestión social? Un caso de estudio. Revista Chilena de Administración Pública, Santiago do Chile (Chile): Universidad del Chile, v. 2 , n. $4,2003 / 2004$.

、 Implicações de mudanças tecnológicas para a administração pública brasileira: o caso Ministério da Fazenda. Cadernos Ebape.br, v. 2, n. 2, 2004. Disponível em: <www.ebape.fgv.br/cadernos>.

、 Inclusão social por meio de parcerias no apoio ao desenvolvimento local. In: CONGRESO INTERNACIONAL DEL CLAD, 9. Anales... Madrid, 2004.

v Inovando com democracia, ainda uma utopia. Novos Cadernos NAEA, Belém: Núcleo de Altos Estudos Amazônicos da Universidade Federal do Pará, v. 2, n. 1, p. 155-168, jun. 1999.

V Manutenção produtiva total: um estudo de caso. Revista Portuguesa e Brasileira de Gestão, Lisboa: Ideg; Rio de Janeiro: Ebape/FGV, v. 2, n. 2, p. 106119, abr./jun. 2003.

v Metodologias participativas, experiências em gestão pública e cidadania. In: ENCONTRO NACIONAL DE ASSOCIAÇÃO NACIONAL DE PÓS-GRADUAÇÃO EM ADMINISTRAÇÃO, 21. Anais... Angra dos Reis: Anpad, 1997.

、 O mito da participação. RAP, Rio de Janeiro: FGV, v. 24, n. 3, 1990.

v O mythos da razão administrativa. RAP, Rio de Janeiro: FGV, v. 27, jul./ set. 1993.

V (Neo)tecnocratas ou (neo)bobos? Eis a questão. Organizações \& Sociedade. Salvador: EA/UFBA, v. 10, n. 26, p. 107-117, jan./abr. 2003.

- Obstáculos a la modernización de los gobiernos locales: la persistencia de formas tradicionales en la dominación política. Un estudio en el Nordeste 
brasileño. In: CONGRESO INTERNACIONAL DEL CLAD, 10. Anales... Santiago de Chile, out. 2005.

v Parcerias em gestão social: uma experiência de organização para o desenvolvimento de comunidades. In: ENCONTRO DA ASSOCIAÇÃO NACIONAL DE PÓS-GRADUAÇÃO EM ADMINISTRAÇÃO, 22. Anais... Foz do Iguaçu, 1998.

- Programa de Capacitação Comunitária para o Desenvolvimento Regional - o local como referência: proposta pedagógica e metodológica (parte I). RAP, Rio de Janeiro: FGV, v. 34, n. 1, p. 261-266, jan./fev. 2000. (Boletim Pegs).

v Programa de Capacitação Comunitária para o Desenvolvimento Regional - o local como referência: proposta pedagógica e metodológica (parte II). RAP, Rio de Janeiro: FGV, v. 34, n. 2, mar./abr. 2000.

v Programa de estudos em gestão social da Ebap/FGV e relato de pesquisas com metodologias participativas. Cadernos de Pesquisa, Rio de Janeiro: DPPEbap/FGV, n. 5, nov. 1993.

v Projetos comunitários: elaborando um referencial teórico. RAP, Rio de Janeiro: FGV, v. 25, n. 3, jul./set. 1991.

- Relatório do marco legal da participação cidadã no município do Rio de Janeiro. Cadernos EBAP, Rio de Janeiro: FGV, n. 95, abr. 1999.

- A sociedade é protagonista na relação com o Estado? Cadernos Gestão Pública e Cidadania, São Paulo: Eaesp/FGV, v. 15, fev. 2000.

$\checkmark$ Superando a ingenuidade: minha dívida a Guerreiro Ramos. RAP, Rio de Janeiro: FGV, v. 31, n. 5, set./out. 1997.

- Tecnologia da informação como instrumento de apoio do analista simbólico. Organizações \& Sociedade, Salvador: Eaufba, v. 5, n. 11, jan./abr. 1998.

$\checkmark$ O trabalho numa perspectiva teórico-crítica: um exercício conceitual. Organizações \& Sociedade, Salvador: Eaufba, v. 4, n. 10, set./dez. 1997.

- Trabalho voluntário: isonomia ou economia? In: ENCONTRO DE ADMINISTRAÇÃO PÚBLICA E GOVERNANÇA (ENAPG). Anais... Rio de Janeiro, 2004.

- Zeus Condena Sísifo. Revista de Administração e Política, Rio de Janeiro: Fundação Escola de Serviço Público do Estado do Rio de Janeiro, ano 15, n. 106, dez. 1992. 
PRÊMIO

、 PREMMIO JORGE OSCAR DE MELLO FLORES — 2000, concedido pela RAP para o artigo "Alianças e parceria: uma estratégia em Alves \& Cia.", RAP, v. 34, n. 3, maio/jun. 2001.

\section{Capacitação}

v Desde 1990 o Pegs desenvolve, no segundo semestre de cada ano, cursos de elaboração, administração e avaliação de projetos comunitários, com apoio da Cáritas Arquidiocesana do Rio de Janeiro, para comunidades vinculadas às pastorais atendidas por essa Arquidiocese. A participação de pessoas, nos 16 anos de atividade, envolveu aproximadamente 110 monitores, alunos do Mestrado em Administração Pública da Ebape, da disciplina gestão social I e cerca de 520 alunos, provenientes de comunidades da cidade do Rio de Janeiro.

、 No âmbito do Programa de Pós-Graduação da Ebape (mestrado e doutorado) são oferecidas as seguintes disciplinas eletivas: gestão social I e II; teoria crítica e teorias organizacionais.

v No Curso Intensivo de Administração Pública (Cipad) são oferecidas as seguintes disciplinas eletivas: gestão de políticas sociais e desenvolvimento local e cidadania.

、 Sob a perspectiva do conceito de gestão social, o Pegs colabora com os seguintes mestrados: Mestrado em Bens Culturais e Projetos Sociais (Cpdoc) FGV) por meio da disciplina gestão de projetos sociais; Mestrado em Desenvolvimento, Gestão e Cidadania (Unijuí), com a disciplina administração pública e desenvolvimento; Núcleo de Pós-Graduação em Desenvolvimento e Gestão Social, da Universidade Federal da Bahia (UFBA), através da disciplina gestão social.

v Curso Administração para Organizações do Terceiro Setor, promovido pela Ebape/FGV, Rio de Janeiro, 2을 semestre de 2002.

v Capacitação do Fórum de Desenvolvimento Local Integrado Sustentável (Dlis) em municípios do Espírito Santo e Rio de Janeiro. Apoio Comunidade Solidária e Sebrae, 1999-2000. 
v I, II e III Cursos de Gestão Social, promovidos pela Casa Civil da Presidência da República/Pnud. Respectivamente, $1^{\underline{0}}$ e $2^{\underline{O}}$ semestres de 1998, $1^{\underline{0}}$ semestre de 1999.

v Workshop Relações Industriais e os Processos de Trabalhos Participativos e Negociados, promovido pela Coppe/UFRJ, Rio de Janeiro, 6 a 8 ago. 1997.

v Curso Capacitação Profissional para Gestão de Organizações do Terceiro Setor, promovido pela Ebape-Eaesp/FGV, Rio de Janeiro, 2 a 6 dez. 1996.

\section{Dissertações}

v Gestão pelas competências em ONGs como uma alternativa de gestão social: pesquisa-ação no Instituto Bola para Frente, da mestranda Silvana Rodrigues de Andrade, do Mestrado Profissionalizante em Bens Culturais e Projetos Sociais do Centro de Pesquisa e Documentação de História Contemporânea do Brasil (Cpdoc/FGV), Rio de Janeiro, 2006.

\ Marketing social, comunicação e participação. Avanços e retrocessos na tentativa de planejar a comunicação de uma ONG de forma participativa. Da mestranda Lucia Cristina Sales de Oliveira, do Mestrado Profissionalizante em Bens Culturais e Projetos Sociais do Centro de Pesquisa e Documentação de História Contemporânea do Brasil (Cpdoc/FGV), Rio de Janeiro, 2006.

、 Exclusão social: gestão estratégica de pessoas em duas subsidiárias de uma empresa multinacional, do mestrando André de Paula Schubert, do Mestrado Executivo da Ebape/FGV, 2006.

v O Conselho Municipal de Desenvolvimento Sustentável e a gestão de recursos hídricos - um estudo na Bacia do Rio Itabapoana (RJ), da mestranda Marília Sant'Anna, do Mestrado Profissionalizante em Bens Culturais e Projetos Sociais do Cpdoc/FGV, Rio de Janeiro, 2005.

v Desenvolvimento local, cidadania e redes sociais: um estudo em Minas Gerais, do mestrando Valdeir Martins de Faria, da Ebape/FGV, Rio de Janeiro, 2005.

v O Projeto Managé e o Conselho Municipal de Desenvolvimento Sustentável, da mestranda Marilia de Sant'Anna Faria, do Mestrado Profissionalizante em Bens Culturais e Projetos Sociais do Cpdoc/FGV, Rio de Janeiro, 2005. 
V Responsabilidade corporativa - entre o social e o regulado: estudo de um setor da siderurgia brasileira, do doutorando Marcelo Fernando López Parra, da Ebape/FGV, Rio de Janeiro, 2004.

、 Responsabilidade social sob a ótica do assédio moral: o caso Furnas, do mestrando Hélio Araújo de Souza Jr., Ebape/FGV, 2003.

v Responsabilidade social e dimensões sociais do marketing: o estudo do caso Furnas, do mestrando Edinelson Benedito A. de Azevedo, Ebape/FGV, 2003.

v Responsabilidade social e educação para a cidadania: o caso Furnas, da mestranda Gláucia Paula B. Guarany, Ebape/FGV, 2003.

v Política pública local e a cadeia produtiva: um estudo de caso, do mestrando Fábio Simone de Souza, Ebape/FGV, 2003.

v Racionalidade comunicativa e processo administrativo em equipes funcionais: o caso do Banco Central do Brasil, do mestrando Wanderley Silva, do Cfap/Ebape/FGV, Rio de Janeiro, 2002.

v Fatores críticos de sucesso na gestão das AABBS - Associações Atléticas Banco do Brasil, do mestrando Antonio Sergio Riede, Ebape/FGV, 2002.

- Responsabilidade social na cadeia produtiva Bosch. O caso Samor, do mestrando Sergio de Mattos Hilst, Ebape/FGV, 2002.

、 Peça por peça: sistematização de um programa de responsabilidade social, do mestrando José Antonio Fares, Ebape/FGV, 2002.

v Responsabilidade social e marketing social: dois estudos de caso, do mestrando Fabiano Christina Pucci do Nascimento, Ebape/FGV, 2002.

v Modelo contemporâneo, modelo de transição ou casa-grande \& senzala? A política de gestão nas Centrais Elétricas Brasileiras S.A. — Eletrobrás, do mestrando Vagner Costa Battaglia, do Cfap/Ebape/FGV, Rio de Janeiro, 2002.

v Responsabilidade social e marketing social: dois estudos de caso, do mestrando Fabiano Christina Pucci do Nascimento, do Cfap/Ebape/FGV, Rio de Janeiro, 2002.

- A participação da sociedade na gestão pública local e na produção das políticas públicas: a atuação dos conselhos municipais em Ijuí - RS, de 1989 a 2000, do mestrando Sérgio Luis Allenbrandt, Ebape/FGV, 2001. 
- Organizações de trabalhadores do setor naval do Rio de Janeiro: novas modalidades na relação capital-trabalho?, do mestrando José Luís Abreu Dutra, Ebape/FGV, 2001.

v Manutenção produtiva total: o caso Eletronorte, do mestrando Jorge Nassar Palmeira, do Cfap/Ebape/FGV, Rio de Janeiro, 2001.

v As dimensões estratégia e sociocomunicacional da rede de terceirização: impactos e perspectivas na visão gerencial, sindical e dos trabalhadores terceirizados, da mestranda Valéria Rosa Bicudo, Ebape/FGV, 2001.

v Modelo de processo avaliativo na administração pública - um estudo de caso, do mestrando Vinicius Adalberto de Souza Barcelos, do Cfap/Ebape, Rio de Janeiro, 2001.

- Responsabilidade social na cadeia produtiva da empresa Bosch: o caso Metapar, da mestranda Simone Samways Lazari, Ebape/FGV, 2001.

v A flexibilização organizacional através de sistemas integrados de gestão no setor industrial, do mestrando Edson Chiari Grottoli, do Cfap/Ebape/FGV, Rio de Janeiro, 2001.

v Projeto de reestruturação organizacional de uma empresa de construção civil: um projeto de consultoria, do mestrando Paulo Gilberto dos Santos Silva, do Cfap/Ebape/FGV, Rio de Janeiro, 2001.

- Responsabilidade social na cadeia produtiva da empresa Bosch: o caso Metapar, da mestranda Simone Samways Lazari, do Cfap/Ebape/FGV, Rio de Janeiro, 2001.

v A origem cultural de um povo como fator de desenvolvimento da indústria: o caso Todeschini S.A., da mestranda Aida Teresinha Fachinelli, do Cfap/Ebape/FGV, Rio de Janeiro, 2001.

v Institucionalização de práticas participativas na administração pública: caminho para democratização do poder local, da mestranda Lessandra da Silva, Ebape/FGV, 2001.

v Projeto Mangueira: ilusão ou inclusão social. Uma experiência em gestão socioesportiva, do mestrando José Antônio Barros Alves, Ebape/FGV, 2000.

v A racionalidade substantiva na avaliação de projetos em ONGs: três casos, da mestranda Liliane Gnocchi da Costa Reis, 2000. 
- Participação cidadã na gestão pública: estudo de caso do Programa FavelaBairro do Município do Rio de Janeiro, da mestranda Gylcilene Ribeiro Storino, Ebape/FGV, 2000.

v Responsabilidade social das organizações: estudo de caso do Banco Central do Brasil, da mestranda Elvira Cruvinel Ferreira Ventura, Ebape/FGV, 1999.

、 Avaliação de programas de desenvolvimento comunitário: o caso do Fundec, do mestrando Walter Facó Bezerra, Ebape/FGV, 1996.

- O orçamento do governo local sob condições de participação dos cidadãos: o caso da Prefeitura de Santos, do mestrando Eugênio Lima Mendes, Ebape/FGV, 1995.

、 Participação popular na gestão pública da saúde - um estudo de caso, da mestranda Iana Maria Campello Passos, Ebape/FGV, 1995.

- Gestão social: as novas relações entre Estado e sociedade na área de abastecimento local, da mestranda Mônica Godinho Ribas, Ebape/FGV, 1994.

、 Política de turismo social no Brasil: mito ou realidade?, do mestrando Jacob Eduardo Rosenberg, Ebape/FGV, 1993. .

v Proposta de uma política pública em ciência e tecnologia para Colômbia, do mestrando Jaime José Triana Restrepo, do Mestrado em Administração Pública da Ebape/FGV, 1992.

\begin{tabular}{|c|c|c|c|c|c|}
\hline \multicolumn{6}{|c|}{ Quantitativo da produção do Pegs - 1990-2006 } \\
\hline $\begin{array}{l}\text { Tipo de } \\
\text { produção }\end{array}$ & $\begin{array}{l}\text { Sociedade- } \\
\text { Estado }\end{array}$ & $\begin{array}{c}\text { Trabalho- } \\
\text { capital }\end{array}$ & $\begin{array}{l}\text { Terceiro } \\
\text { setor }\end{array}$ & Conceituais* & Total \\
\hline Artigos & 17 & 7 & 3 & 15 & 42 \\
\hline Dissertações & 14 & 21 & 4 & - & 39 \\
\hline Tese & - & 1 & - & - & 1 \\
\hline Livros publicados & 1 & 4 & 5 & 2 & 12 \\
\hline Capitulos de livros & 2 & - & - & 2 & 4 \\
\hline Pesquisas & 6 & 2 & 5 & 2 & 15 \\
\hline Trabalhos técnicos & 2 & 1 & 3 & 3 & 9 \\
\hline Total geral & 42 & 36 & 20 & 24 & 122 \\
\hline
\end{tabular}




\section{Referências bibliográficas}

DEMO, Pedro. Participação é conquista. São Paulo: Cortez, 2001.

HABERMAS, Jürgen. Teoria de la acción comunicativa. Madrid: Taurus, 1987. v. 1 e 2.

TENÓRIO, Fernando G. Gestão social: uma perspectiva conceitual. RAP, Rio de Janeiro: FGV, v. 32, n. 5, p. 7-23, set./out. 1998.

- (Re)visitando o conceito de gestão social. In: LIANZA, Sidney; ADDOR, Felipe (Orgs.). Tecnologia e desenvolvimento social e solidário. Porto Alegre: UFRGS, 2005.

; ROSENBERG, J. E. Gestão pública e cidadania: metodologias participativas em ação. RAP, Rio de Janeiro: FGV, v. 31, n. 4, p. 101-125, jul./ago. 1997. 